\title{
Immediate Effects and Safety of High-Frequency Chest Wall Compression Compared to Airway Clearance Techniques in Non-Hospitalized Infants With Acute Viral Bronchiolitis
}

\author{
Vanesa González-Bellido, Verónica Velaz-Baza, Elena Blanco-Moncada, \\ Maria del Carmen Jimeno Esteo, Juan Nicolás Cuenca-Zaldívar, Alicia Colombo-Marro, \\ Márcio Vinícius Fagundes Donadio, and Rodrigo Torres-Castro
}

\begin{abstract}
BACKGROUND: No studies have investigated the use and safety of high-frequency chest wall compression (HFCWC) for non-hospitalized infants with acute viral bronchiolitis (AVB). The aim of the present study was to evaluate the immediate effects and safety of HFCWC as compared to airway clearance techniques in children with AVB. METHODS: In this randomized clinical trial in non-hospitalized infants (0-12 months old) with mild to moderate $\mathrm{AVB}$, children were randomized into 2 groups: airway clearance techniques (20 min of prolonged slow expiration and provoked cough) or HFCWC (15 min). A single session was performed and children were evaluated at baseline and at $10 \mathrm{~min}$ and $20 \mathrm{~min}$ after treatments. Outcomes measures were the Wang severity score, $\mathrm{S}_{\mathrm{pO}_{2}}$, sputum wet-weight, and the presence of adverse events. RESULTS: A total of 91 infant subjects, mean age $7.9 \pm 2.6$ months, were included. Significant $(P=.004)$ between-group differences were found in the Wang score, which was 0.28 points lower in the airway clearance techniques group. There was a greater increase of infants classified as normal and a greater decrease of those classified as mild according to the Wang score when airway clearance techniques were used compared to the use of HFCWC $(P=.009)$. The sputum wetweight was lower in subjects treated with the airway clearance techniques $(P<.001)$. Although $\mathrm{S}_{\mathrm{pO}_{2}}$ improved in both groups, no differences were found between them. There was also no difference for adverse events, and the majority of children did not present any adverse events after $20 \mathrm{~min}$. CONCLUSIONS: The use of HFCWC induced similar clinical effects as airway clearance techniques and was safe for non-hospitalized infants with AVB. Both techniques reduced respiratory symptoms and acutely improved $\mathrm{S}_{\mathrm{pO}_{2}}$. (ClinicalTrials.gov: $\mathbf{N C T 0 3 8 3 5 9 3 6 . ) ~ K e y ~ w o r d s : ~ a c u t e ~ v i r a l ~ b r o n c h i o l i t i s ; ~ h i g h - f r e - ~}$ quency chest wall oscillation; prolonged slow expiration; safety. [Respir Care 2021;66(3):425-433. (C) 2021 Daedalus Enterprises]
\end{abstract}

\section{Introduction}

Acute viral bronchiolitis (AVB) is the most common respiratory disease in children under $1 \mathrm{y}$ of age, with

Ms González-Bellido, Ms Velaz-Baza, and Ms Blanco-Moncada are affiliated with the Fisiobronquial Physiotherapy Clinic, Coslada, Madrid, Spain. Ms Jimeno Esteo is affiliated with the Fisiobronquial Physiotherapy Clinic, Coruña, Galicia, Spain. Mr Cuenca-Zaldívar is affiliated with the Rehabilitation Service, Guadarrama Hospital, Guadarrama, Spain. Mr Cuenca-Zaldívar is affiliated with the School of Health Sciences, Francisco de Vitoria University, Madrid, Spain. Dr Colombo-Marro is affiliated with the Pediatric Service, Babynat Clinic, Madrid, Spain. Dr Donadio is affiliated with the Laboratory of Pediatric Physical Activity, Infant Center, Pontifícia Universidade Católica do respiratory syncytial virus being the main infectious agent, accounting for approximately $80 \%$ of cases. ${ }^{1}$ AVB is usually a mild to moderate disease, characterized by acute inflammation, edema, increased mucus production, and bronchospasm, as well as symptoms such as cough,

\footnotetext{
Rio Grande do Sul, Porto Alegre, Brazil. Dr Torres-Castro is affiliated with the Department of Physical Therapy, Faculty of Medicine, University of Chile, Santiago, Chile.

Dr Donadio is supported in part by Coordenação de Aperfeiçoamento de Pessoal de Nível Superior and Conselho Nacional de Desenvolvimento Científico e Tecnológico. The other authors have disclosed no conflicts of interests.
} 
rhinorrhea, and difficulty of breathing. ${ }^{2}$ It is estimated that approximately one third of children develop the disease during the first year of life, although only 2-3\% will require hospitalization. $^{3}$

The virus produces necrosis and edema of the bronchial epithelium, which causes destruction of ciliated cells; this increases cellular debris and mucus production, which can lead to hyperinflation and atelectasis. ${ }^{4,5}$ Considering that airway clearance techniques allow for the elimination of bronchial secretions, thereby decreasing airway resistance, improving gas exchange, and reducing respiratory load, its use has been long investigated for infants with AVB. ${ }^{6}$ However, there is still conflicting evidence to support its routine use in hospitalized children. ${ }^{3,7-9}$ In addition, very little is known about its effects in non-hospitalized children with AVB.

Techniques based on passive expiration, such as prolonged slow expiration, appear to be more effective than conventional techniques. ${ }^{9,10}$ Preliminary results with prolonged slow expiration, which is a slow, passive, and progressive expiration from functional residual capacity to expiratory reserve volume, suggest that this technique improves clinical symptoms of moderately affected children with AVB. ${ }^{11}$ High-frequency chest wall compression (HFCWC) consists of an inflatable vest device with tubes connected to a remote air pressure generator. ${ }^{12}$ This treatment improves airway secretion clearance in individuals with COPD, ${ }^{13,14}$ neuromuscular diseases,${ }^{15-17}$ and asthma and COPD exacerbation, ${ }^{18-20}$ and in tracheostomized individuals $^{12}$ and patients with acute respiratory failure. ${ }^{21}$ However, to date, there is no study investigating its use for infants with AVB. Evidence from cystic fibrosis studies indicate that the use of HFCWC increases the amount of mucus cleared from the airways. ${ }^{22-25}$ In addition, one in vitro study reported that the oscillated flow may change the physical properties of the mucus. ${ }^{26}$

Considering that the effects and safety of chest physiotherapy has been poorly investigated in non-hospitalized children with AVB and that no studies have evaluated the immediate effects of HFCWC, we sought to evaluate the immediate effects and safety of HFCWC as compared to airway clearance techniques in non-hospitalized infants under 12 months of age with mild to moderate AVB. We hypothesized that HFCWC would present similar effects and safety of previously studied airway clearance techniques and, consequently, could be an alternative for treatment in out-patient settings.

\footnotetext{
Correspondence: Juan Nicolás Cuenca Zaldívar PT MsD, School of Health Sciences, Francisco de Vitoria University, Ctra. Pozuelo-Majadahonda KM 1.800, 28223 Pozuelo de Alarcón, Madrid, Spain. E-mail: j.cuenca.prof@ufv.es.
}

DOI: $10.4187 /$ respcare.08177

\section{QUICK LOOK}

\section{Current knowledge}

Acute viral bronchiolitis is a disease with high health costs and morbidity. High-frequency chest wall compression has been used for infants with several chronic respiratory conditions, although its effects and safety for non-hospitalized infants with acute viral bronchiolitis has not been tested.

\section{What this paper contributes to our knowledge}

The use of high-frequency chest wall compression was shown to be safe for use in non-hospitalized infants with acute viral bronchiolitis. In addition, it induced similar acute clinical effects when compared to the use of prolonged slow expiration, including a reduction in respiratory symptoms of bronchial obstruction and improvement of $\mathrm{S}_{\mathrm{pO}_{2}}$.

\section{Methods}

\section{Design}

This randomized controlled clinical trial with 2 parallel groups was performed in an out-patient setting. The study followed the Consolidated Standards of Reporting Trials guidelines. ${ }^{27}$ All parents or legal guardians signed an informed consent form before recruitment. The study was approved by the University Research Ethics Committee (approval number 31/2018). All procedures were conducted in compliance with the amended Declaration of Helsinki.

\section{Subjects}

A convenience sample of 91 children was recruited between March and May 2019. The following inclusion criteria were used: age $2-12$ months, time from diagnosis to inclusion in the study $<48 \mathrm{~h}$, AVB classified as mild to moderate with a Wang clinical severity score $\leq 8$, and not having received airway clearance techniques previously since their diagnosis. The exclusion criteria used were: severe AVB with a Wang clinical score $>9$; associated cardiac, neurological, or traumatic disease; previous hospitalization for wheezing; and medical diagnosis of recurrent wheezing.

\section{Intervention}

The children were randomized into 2 groups: airway clearance techniques (ie, prolonged slow expiration and provoked cough) and HFCWC (SmartVest, Electromed, New Prague, Minnesota). In both groups, infants began the 


\section{High-Frequency Chest Wall Compression in Bronchiolitis}

study after $2 \mathrm{~h}$ of fasting and without exceeding $2 \mathrm{~h}$ since their last bronchodilator inhalation. An independent investigator allocated subjects to the airway clearance techniques or HFCWC group in a concealed manner, using sealed opaque envelopes. In each envelope, the number of assignment to either of the 2 groups was included; these numbers were generated by simple random sequences using $\mathrm{R}$ 5.3.1. ( $\mathrm{R}$ Foundation for Statistical Computing, Vienna, Austria). In both groups, all children received 1 inhalation with $4 \mathrm{~mL}$ hypertonic saline $(\mathrm{NaCl} 3 \%)$, nebulized at a flow of 8 L/min over 10 min (Phillips, Murrysville, Pennsylvania).

The protocol for airway clearance techniques consisted of a standard 20-min session using the prolonged slow expiration technique. ${ }^{28}$ After its application, coughing was manually triggered by applying a tracheal pressure at the end of the inspiratory phase. Regarding the HFCWC group, the SmartVest system consisting of an inflatable HFCWC connected by a tube to a remote air pressure generator was used. The HFCWC was used for $15 \mathrm{~min}$ at a frequency of $12 \mathrm{~Hz}$ and at a pressure setting of $2-4 \mathrm{~cm} \mathrm{H}_{2} \mathrm{O}$, according to the subject's comfort. Each subject was fitted with an appropriately sized, full-torso, inflatable, disposable HFCWC connected to the air pulse. All techniques used in both groups were performed by experienced and trained physiotherapists.

\section{Outcome Measurements}

A medical evaluator, blinded to the group allocation, was responsible for all evaluations in both groups, including the classification of infants according to the initial (baseline) clinical severity score (Wang), ${ }^{29}$ as well as measuring the $\mathrm{S}_{\mathrm{pO}_{2}}$ using a pulse oximeter (Radical Touchscreen, Masimo, Irvine, California), heart rate, and breathing frequency. These measurements were performed at baseline and at $10 \mathrm{~min}$ and 20 min after each treatment was applied.

The primary end point was the Wang clinical severity score, which is a quantitative accumulative scale designed to evaluate clinical severity in infants with AVB. The scoring system is composed of 4 items: breathing frequency, wheezing, chest retraction, and general condition. Each item is scored as mild (1-3), moderate (4-8), or severe $(>8)$. The maximum score is 12 , and 0 is the minimum score, indicating normality; thus, a higher score indicates a worse condition. ${ }^{29}$ The different variables used within the Wang score have a good level of inter-observer concordance among doctors, nurses, and physiotherapists (kappa $=$ $0.72,95 \%$ CI $0.66-0.78),{ }^{30}$ as well as an excellent level of intra-observer agreement (intraclass correlation coefficient $=0.99)$ with moderate validity $(\mathrm{r}=0.44),{ }^{31}$ its use is recommended in research to assess the severity of AVB in infants. The secondary outcome was the wet-weight of the sputum expectorated during the treatment session. Total secretions expectorated during the intervention were collected, wet-weighed on digital scales (Model BA 2105, Sartorius Fine, Göttingen, Germany) and quantified by an unblinded assessor. Adverse events, including the presence of petechiae, tachycardia, and vomiting, were monitored during both treatments and recorded at baseline and at 10 min and $20 \mathrm{~min}$.

\section{Sample Size}

Due to the absence of similar previous studies, the final Wang score of the first 20 children included in the study was used to calculate the required sample size. The estimation indicated that 45 children per group were necessary, accepting a risk of a type- 1 error of $\alpha=0.05$ and a power of $90 \%$.

\section{Statistical Analysis}

Statistical analysis was performed using $\mathrm{R}$ 5.3.1. The level of significance was set at $P<.05$. The Shapiro-Wilk test was used to determine the non-normal distribution of quantitative variables. Qualitative variables are described as absolute values and relative frequencies, and quantitative variables are described as medians and interquartile ranges or means and standard deviations. Quantitative outcome variables were analyzed using a robust mixed analysis of variance (ANOVA) with trimmed means, with one factor within subjects (repeated measurements) and one factor between subjects (groups). The Mann-Whitney $U$ test with Bonferroni correction was applied as a post hoc test and to analyze the final mucus volume. Qualitative outcome variables were analyzed with the Cochran-Mantel-Haenszel test using the Pearson chi-square with Bonferroni correction as a post hoc test. The effect size for the quantitative variables was defined with the partial $\eta^{2}$ as $0.01-0.06$ (small), 0.060.14 (moderate), and $>0.14$ (large) and with the $\mathrm{r}$ statistic for final mucus volume defined as $0.1-0.4$ (small), 0.4-0.6 (moderate), and $>0.6$ (large). For the categorical variables, effect sizes were determined using Cramer V, where 0.1$0.3,0.3-0.5$, and $>0.5$ indicated small, moderate, and large effect sizes, respectively.

\section{Results}

In total, 785 children were assessed for selection, and 694 were excluded. The reasons for exclusion and the study flow chart are presented in Figure 1. The final sample consisted of 91 children randomized to airway clearance techniques $(n=44)$ and HFCWC $(n=47)$. The baseline characteristics of the subjects are shown in Table 1 . The mean age of the infants was $7.9 \pm 2.6$ months. No significant baseline differences between the 2 groups were found. 


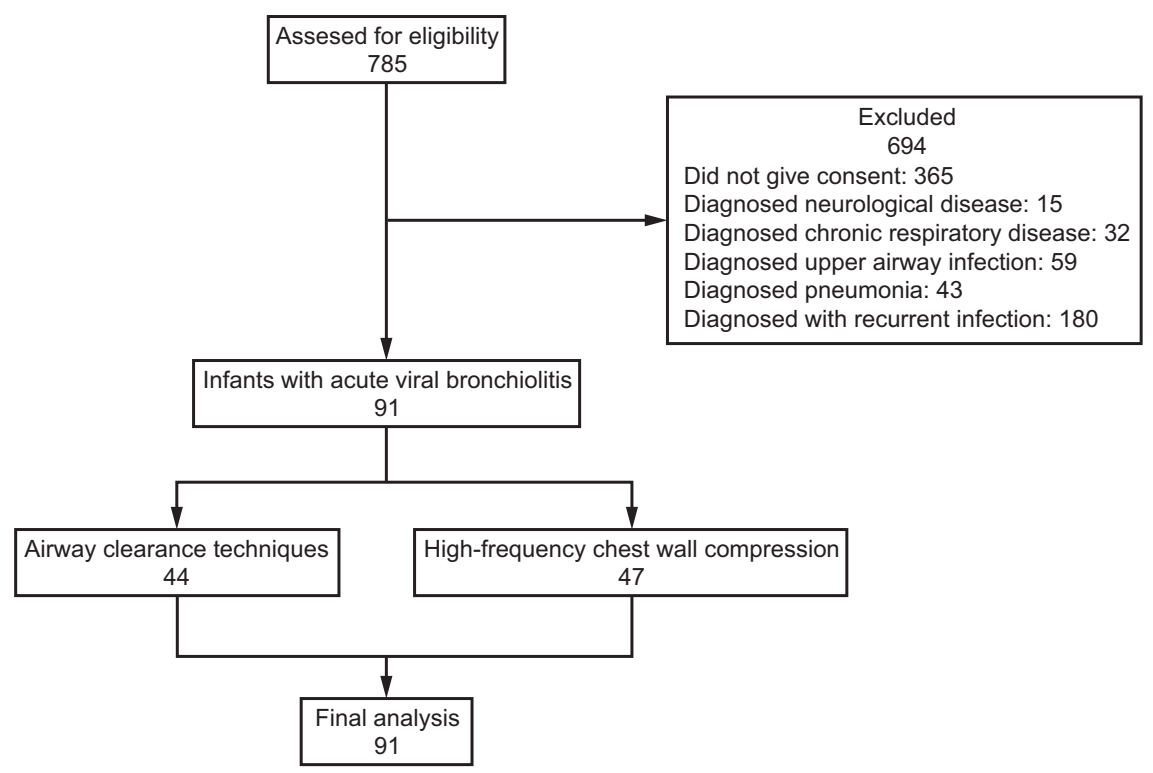

Fig. 1. Flow chart.

Table 1. Baseline Subject Characteristics

\begin{tabular}{lccc}
\hline \hline & $\begin{array}{c}\text { Airway Clearance } \\
\text { Techniques } \\
(n=44)\end{array}$ & $\begin{array}{c}\text { HFCWC } \\
(n=47)\end{array}$ & $P$ \\
\hline Age, months & $7.53 \pm 2.68$ & $8.18 \pm 2.43$ & .21 \\
Female & $17(38.6)$ & $15(31.9)$ & .65 \\
Weight, kg & $8.08 \pm 1.53$ & $8.21 \pm 1.21$ & .43 \\
Height, cm & $68.90 \pm 7.79$ & $69.70 \pm 6.56$ & .79 \\
$\mathrm{~S}_{\mathrm{pO}_{2}}, \%$ & $95.30 \pm 2.31$ & $95.43 \pm 2.04$ & .77 \\
Frequency, breaths/min & $48.59 \pm 8.01$ & $45.53 \pm 6.57$ & .05 \\
Use of medications & $11(25.0)$ & $8(17.0)$ & .49 \\
$\quad$ No & $3(6.8)$ & $2(4.3)$ & .94 \\
$\quad$ Bronchodilator & $3(6.8)$ & $6(12.8)$ & .55 \\
$\quad$ (salbutamol) & & & \\
Presence of skin atopy & $5(11.4)$ & $7(14.9)$ & .85 \\
Gestational age & $39(88.6)$ & $40(85.1)$ & \\
$\quad$ Pre-term & $7(15.9)$ & $7(14.9)$ & $>.99$ \\
$\quad$ Term & & & \\
$\quad$ Gastroesophageal reflux & & & \\
& & & \\
\end{tabular}

Data are expressed as mean $\pm \mathrm{SD}$ or $n(\%)$. HFCWC $=$ high-frequency chest wall compression.

The mixed ANOVA test showed significant differences in the group $\times$ time interaction of the Wang score $(F$ $(2,46.811)=6.09, P=.004)$, with a difference between groups of 0.149 (95\% CI $0.042-0.383$ ) points lower in the airway clearance techniques compared to the HFCWC group $(0.14 \pm 0.46$ vs $0.28 \pm 0.54$, respectively), although with a small effect size $\left(\eta^{2}=0.007\right.$, 95\% CI 0-0.07). There were also significant differences in the group $\times$ time interaction for breathing frequency $(\mathrm{F}(2,46.938)=6.584, P=.003)$, with a difference of
0.277 breaths/minute (95\% CI $0.468-1.34)$ when comparing both groups $(27.89 \pm 1.93$ vs $28.11 \pm 2.40)$ and a small effect size $\left(\eta^{2}=0.007,95 \%\right.$ CI $\left.0.003-0.11\right)$, and for heart rate $(\mathrm{F}(2,46.571)=5.943, P=.005)$, which was lower in the airway clearance techniques group than in the HFCWC group $(111.00 \pm 13.02$ vs $116.60 \pm 20.03$ ) with a difference of 5.87 beats $/ \mathrm{min}$ (95\% CI $0.723-13.2)$ and a small effect size $\left(\eta^{2}=\right.$ $0.006,95 \%$ CI $0.012-0.11)$. No significant differences $(P=.32)$ between groups were found for $\mathrm{S}_{\mathrm{pO}_{2}}$ (Fig. 2).

The Mann-Whitney $U$ test also showed a significant between-group difference in the final mucus volume $(\mathrm{Z}=$ $-3.884, P<.001)$, which was lower in the airway clearance techniques group than in the HFCWC group (median [interquartile range]: 19 [10-24.5] mL vs 30 [20-50] mL), with a between-group difference of $16.8 \mathrm{~mL}(95 \% \mathrm{CI}$ 7.52-26.24) and a moderate effect size $(\mathrm{r}=0.407,95 \%$ CI 0.239-0.572) (Fig. 3). The Cochran-Mantel-Haenszel test revealed significant associations between the levels of the Wang score across groups and times of measurements $\left(\mathrm{X}^{2}(2)=9.534, P=.009\right)$, with a higher reduction in the number of infants with a mild level in the airway clearance techniques compared to the HFCWC group (54.5\% to $9.1 \%$ vs $61.7 \%$ to $23.4 \%$ ) and a higher increase in infants with a normal level $(0 \%$ to $90.9 \%$ vs $0 \%$ to $76.6 \%$ ), presenting a medium effect size (Cramer $\mathrm{V}=$ $0.193,95 \%$ CI 0-1) (Fig. 4).

Regarding the presence of adverse effects, the CochranMantel-Haenszel test showed no significant differences between groups $\left(\mathrm{X}^{2}(3)=4.565, P=.207\right)$. In the majority of infants (airway clearance techniques group: 95.5\%; HFCWC group: $83.0 \%$ ), no adverse events were present after $20 \mathrm{~min}$. Taken together, the results indicate that adverse 

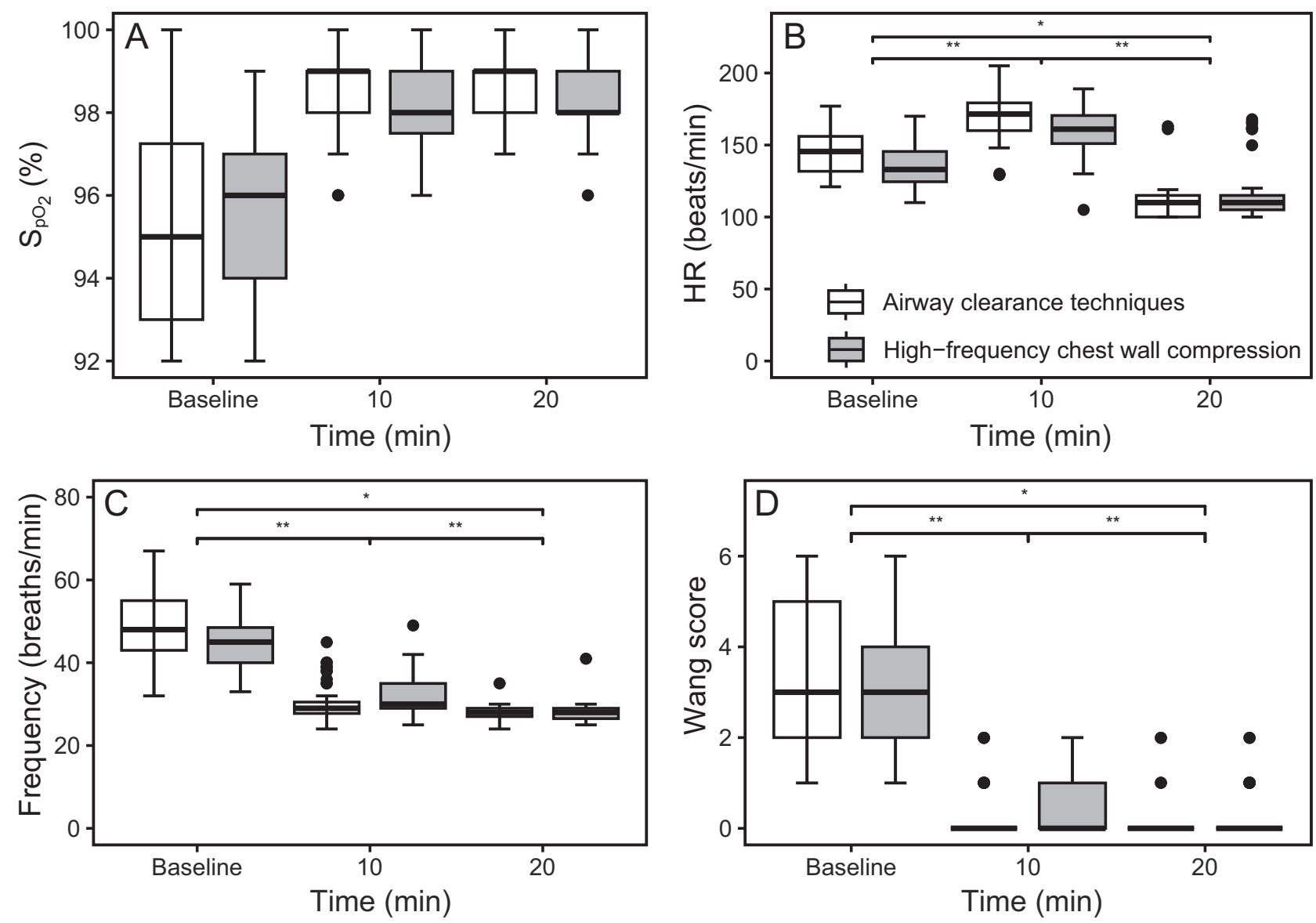

Fig. 2. Immediate effects of high-frequency chest wall compression and airway clearance techniques on (A) $\mathrm{S}_{\mathrm{pO}}$, (B) heart rate, (C) breathing frequency, and (D) Wang score. Measurements were performed at baseline and at $10 \mathrm{~min}$ and 20 min after treatment. *Significant differences with $P<.01$ (robust ANOVA). ${ }^{\star *}$ Significant differences with $P<.001$ (post hoc tests).

events were uncommon and transitory for both groups (Table 2).

\section{Discussion}

This randomized controlled trial assessed the immediate effects and safety of HFCWC compared to prolonged slow expiration in non-hospitalized children with mild to moderate AVB. To our knowledge, this is the first clinical trial performed in an out-patient setting to evaluate the shortterm benefits and safety of HFCWC in children with AVB. The results have shown that the use of HFCWC produced similar immediate effects compared to prolonged slow expiration, and no clinically relevant adverse events were observed.

Wheezing and coughing are common symptoms of bronchial obstruction in children, ${ }^{32}$ and the Wang score is a validated practical clinical tool to evaluate it. ${ }^{29}$ In our study, $65.9 \%$ of subjects showed normal Wang score levels immediately after the treatment session, and no infant presented with moderate levels. Although there was an increase in the proportion of infants presenting a normal Wang score 10 min after treatment in both groups, infants in the airway clearance techniques group presented a higher proportion compared to the HFCWC group (77.3\% vs $53.2 \%)$. There was also a greater decrease in children classified with a mild Wang score in the airway clearance techniques group compared to the HFCWC group. Inflammation, edema, and necrosis of the epithelial cells are characteristics of AVB, resulting in bronchial hypersecretion with airway obstruction. ${ }^{33,34}$ The drainage of secretions is supposed to be the main mechanism of action of airway clearance techniques maneuvers, considering that these techniques may not affect edema or bronchospasm. In addition, the deflation obtained by slow and deep expiration enables more clearance of distal air pathways, which constitute the central part of the bronchopulmonary obstruction. ${ }^{28}$ Thus, both effects induced by airway clearance techniques may help decrease bronchial obstruction resulting from AVB. Our results indicate that both prolonged slow expiration and HFCWC acutely promoted these effects and reduced airway obstruction, as indicated by the Wang score. 
High-Frequency Chest Wall Compression in Bronchiolitis

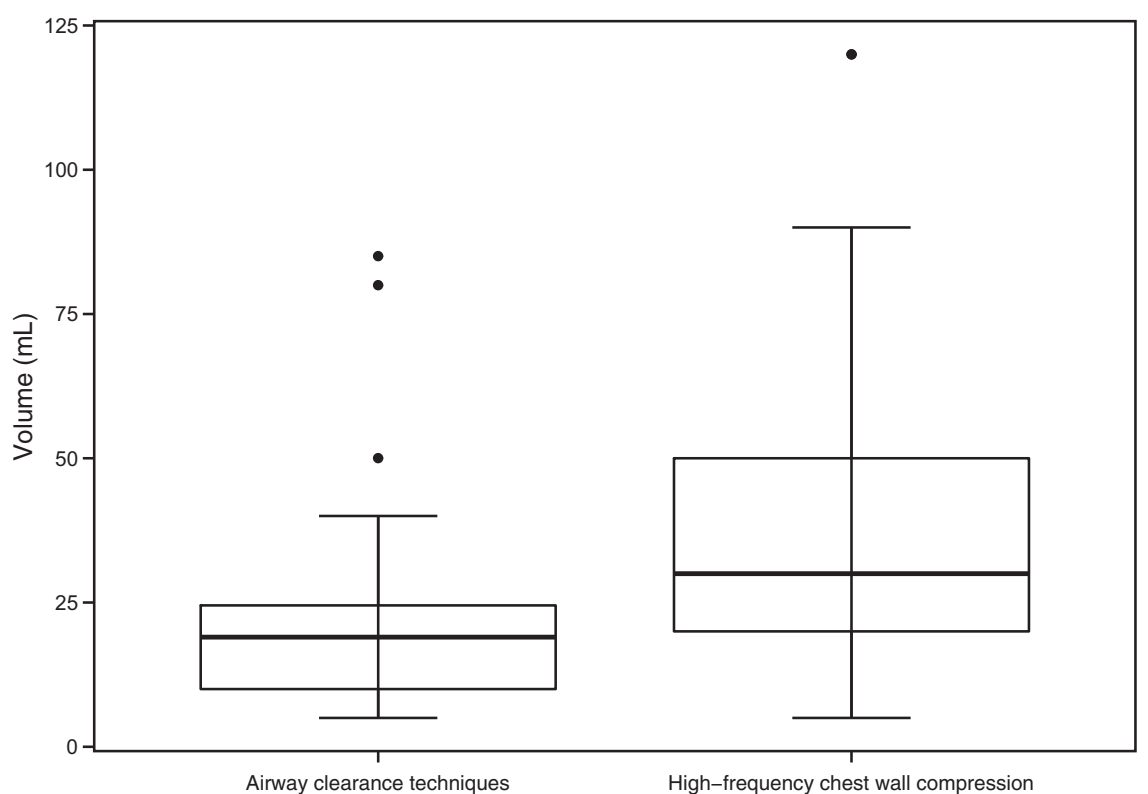

Fig. 3. Effects of high-frequency chest wall compression and airway clearance techniques on the sputum wet-weight. Collection was performed during the treatment period.
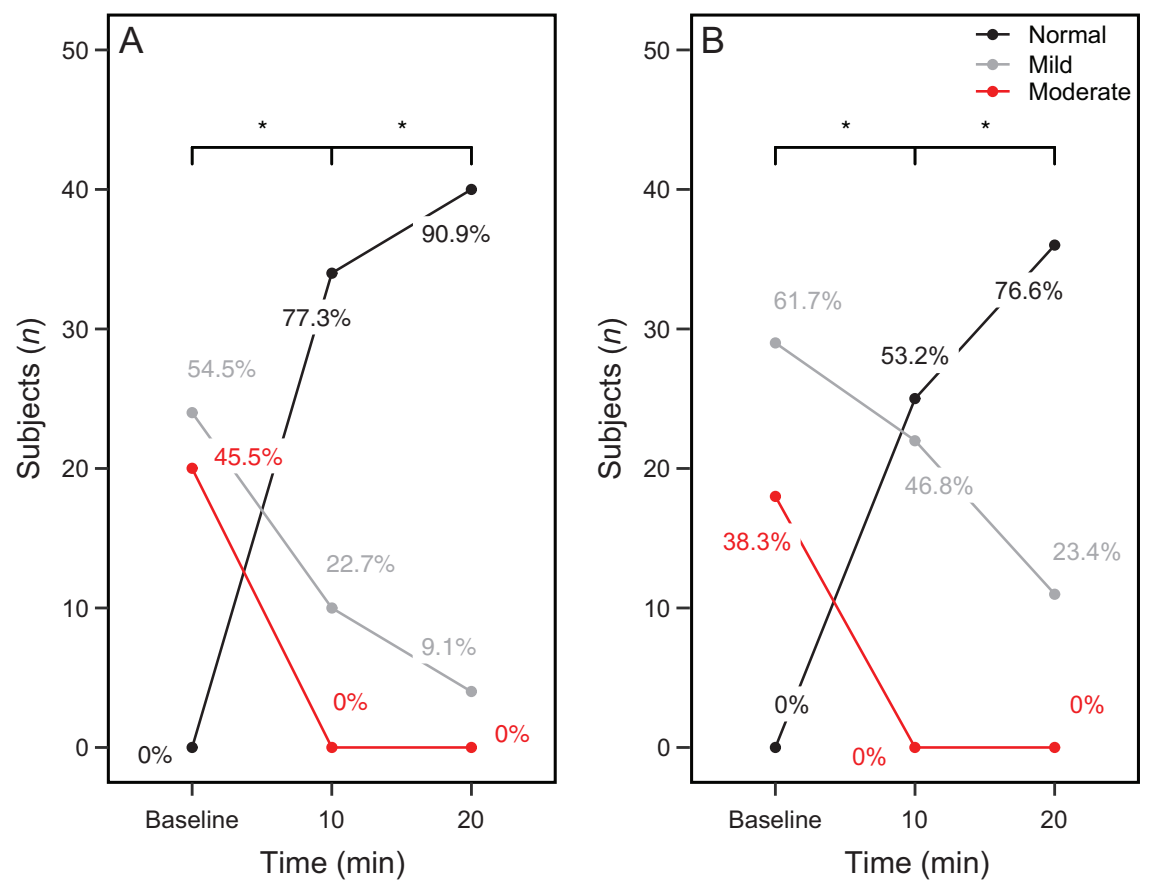

Fig. 4. Immediate effects of (A) airway clearance techniques and (B) high-frequency chest wall compression on the percent of infants classified in each level of the Wang score. Measurements were performed at baseline and at $10 \mathrm{~min}$ and $20 \mathrm{~min}$ after treatment. *Significant differences with $P<.01$ (Cochran-Mantel-Haenszel test).

The volume of the expectorated phlegm correlates with the level of obstruction, and one of the main objectives of airway clearance techniques is to mobilize and clear secretions in the airways to improve pulmonary ventilation and decrease the work of breathing. Prolonged slow expiration and HFCWC are both effective in removing secretions quickly from the respiratory tract. However, there are no previous studies measuring the amount of sputum (wet or dry weight) after an intervention in infants with AVB. ${ }^{6}$ In our study, there was a significant between-group difference in the final wet sputum volume $(\mathrm{Z}=2.262, P<.001)$, which was lower in the airway clearance techniques group 


\section{High-Frequency Chest Wall Compression in Bronchiolitis}

Table 2. Adverse Events at Baseline and at 10 Min and 20 Min After Treatment

\begin{tabular}{|c|c|c|c|c|c|c|c|c|}
\hline & \multicolumn{3}{|c|}{ Airway Clearance Techniques } & \multicolumn{3}{|c|}{ High-Frequency Chest Wall Compression } & \multirow{2}{*}{$P$} & \multirow{2}{*}{ Cramer V $(95 \% \mathrm{CI})$} \\
\hline & Baseline & $10 \mathrm{Min}$ & 20 Min & Baseline & $10 \mathrm{Min}$ & 20 Min & & \\
\hline None & $0(0)$ & $12(27.3)$ & $42(95.5)$ & $0(0)$ & $21(44.7)$ & $39(83.0)$ & .21 & $0.21(0-1)$ \\
\hline Petechiae & $0(0)$ & $0(0)$ & $0(0)$ & $0(0)$ & $1(2.1)$ & $1(2.1)$ & & \\
\hline Tachycardia & $0(0)$ & $32(72.7)$ & $2(4.5)$ & $0(0)$ & $24(51.1)$ & $6(12.8)$ & & \\
\hline Vomiting & $0(0)$ & $0(0)$ & $0(0)$ & $0(0)$ & $1(2.1)$ & $1(2.1)$ & & \\
\hline
\end{tabular}

compared to the HFCWC group (median [interquartile range]: 19 [10-24.5] vs 30 [20-50]). This study was powered to detect a difference of $11 \mathrm{~g}$ of expectorated sputum between groups during a single treatment session, although other studies have been based on a difference of 3-3.5 g, which is generally accepted as a clinically important difference. ${ }^{35,36}$ On the other hand, there are authors who believe that wet sputum data may not be clinically relevant because wet sputum is often mixed with salivary secretions ${ }^{37}$ and may therefore overestimate the amount of real bronchial secretions, leading to measurement error. However, previous work has found wet weight to be proportional to dry weight sputum. ${ }^{35,38}$ Emerging noninvasive methods of measuring airway clearance may be more sensitive indicators in the future (eg, the lung clearance index and electrical impedance tomography). ${ }^{39}$ Although it was not possible to identify the precise mechanisms accounting for the sputum weight differences between groups, it is possible that the number and frequency of provoked coughs may play a role, as this was not standardized. On the other hand, it seems important to apply techniques as close to real-life clinical use as possible.

Some authors have reported "uncomfortable" effects for children during respiratory physiotherapy, including resistance or crying during therapy, thus diminishing the effectiveness or the expected effects. ${ }^{40,41}$ In our study, we did not observe clinically relevant presence of crying, increased episodes of reflux, or reduced $\mathrm{S}_{\mathrm{pO}_{2}} \cdot \mathrm{S}_{\mathrm{pO}_{2}}$ is a quantitatively objective and reliable variable that helps physiotherapists monitor safety, as children who present with a $\mathrm{S}_{\mathrm{pO}_{2}} \leq 92 \%$ should receive oxygen. Keating et $\mathrm{al}^{21}$ published the first case report on the use of HFCWC for secretion clearance in a severely weak child with type 1 spinal muscular atrophy. As in our study, the use of HFCWC was considered safe and there were no desaturations during sessions with HFCWC or with conventional post-HFCWC physiotherapy. More recent research ${ }^{39}$ recommends an individual tuning method to identify optimal treatment frequencies. The effectiveness of HFCWC is directly related to oscillatory flow in the airways ${ }^{42}$; thus, an effective chest wall pulse pressure must be generated for HFCWC to be effective. Infants' comfort is highly correlated with the pulse pressure of the chest wall; in our study, no infants in the HFCWC group had to be excluded due to adverse outcomes such as pain, discomfort, or difficulty tolerating the therapy, thus indicating its safety within the described parameters. Yuan et $\mathrm{al}^{43}$ also reported that HFCWC is safe and tolerable in pediatric subjects with childhood cerebral palsy and neuromuscular diseases. In general, our study had only few and transitory adverse events that were present in both airway clearance techniques and HFCWC groups.

This study has some limitations. First, only the immediate effects were evaluated, which does not allow us to extrapolate results for continuing daily therapy use, although it is possible that increasing the number of interventions would only improve the results by reducing respiratory symptoms. Second, the study has no control group (salbutamol and hypertonic saline only) to compare to airway clearance techniques and HFCWC groups. Although it was not possible to separate the effects of hypertonic saline and salbutamol, the use of airway clearance techniques and HFCWC combined with bronchodilator and hypertonic saline are more representative of current clinical use in an out-patient setting.

\section{Conclusions}

The results of this study indicate that the use of HFCWC induced clinical effects similar to those observed with airway clearance techniques and was safe for non-hospitalized infants with mild to moderate AVB. Both techniques significantly reduced some respiratory symptoms of bronchial obstruction and acutely improved $\mathrm{S}_{\mathrm{PO}_{2}}$. These findings should be further explored in future randomized controlled trials using daily HFCWC for non-hospitalized children with AVB.

\section{REFERENCES}

1. Nair H, Nokes DJ, Gessner BD, Dherani M, Madhi SA, Singleton RJ, et al. Global burden of acute lower respiratory infections due to respiratory syncytial virus in young children: a systematic review and meta-analysis. Lancet 2010;375(9725):1545-1555.

2. Barr R, Green CA, Sande CJ, Drysdale SB. Respiratory syncytial virus: diagnosis, prevention and management. Ther Adv Inf Dis 2019;6:2049936119865798. 


\section{High-Frequency Chest Wall Compression in Bronchiolitis}

3. Ralston SL, Lieberthal AS, Meissner HC, Alverson BK, Baley JE, Gadomski AM, et al. Clinical practice guideline: the diagnosis, management, and prevention of bronchiolitis. Pediatrics 2014;134(5): e1474-e1502.

4. Alvarez AE, Marson FAdL, Bertuzzo CS, Arns CW, Ribeiro JD. Epidemiological and genetic characteristics associated with the severity of acute viral bronchiolitis by respiratory syncytial virus. J Pediatr (Rio J) 2013;89(6):531-543.

5. Teshome G, Gattu R, Brown R. Acute Bronchiolitis. Pediatr Clin North Am 2013;60(5):1019-1034.

6. Gomes GR, Donadio MVF. Effects of the use of respiratory physiotherapy in children admitted with acute viral bronchiolitis. Arch Pediatr 2018;25(6):394-398.

7. Sánchez Bayle M, Martín Martín R, Cano Fernández J, Martínez Sánchez G, Gómez Martín J, Yep Chullen G, García García MC. Estudio de la eficacia y utilidad de la fisioterapia respiratoria en la bronquiolitis aguda del lactante hospitalizado. Ensayo clínico aleatorizado y doble ciego. An Pediatría 2012;77(1):5-11.

8. Roqué i Figuls M, Giné-Garriga M, Granados Rugeles C, Perrotta C, Vilaró J. Chest physiotherapy for acute bronchiolitis in paediatric patients between 0 and 24 months old. Cochrane Database Syst Rev 2016;2:CD004873.

9. Conesa-Segura E, Reyes-Dominguez SB, Ríos-Díaz J, Ruiz-Pacheco MÁ, Palazón-Carpe C, Sánchez-Solís M. Prolonged slow expiration technique improves recovery from acute bronchiolitis in infants: FIBARRIX randomized controlled trial. Clin Rehabil 2019;33 (3):504-515.

10. Hess DR. Airway clearance: physiology, pharmacology, techniques, and practice. Respir Care 2007;52(10):1392-1396.

11. Postiaux G, Louis J, Labasse HC, Gerroldt J, Kotik A-C, Lemuhot A, Patte C. Evaluation of an alternative chest physiotherapy method in infants with respiratory syncytial virus bronchiolitis. Respir Care 2011;56(7):989-994.

12. Bidiwala A, Volpe L, Halaby C, Fazzari M, Valsamis C, Pirzada M. A comparison of high frequency chest wall oscillation and intrapulmonary percussive ventilation for airway clearance in pediatric patients with tracheostomy. Postgrad Med 2017;129 (2):276-282.

13. Piquet J, Brochard L, Isabey D, de Cremoux H, Chang HK, Bignon J, Harf A. High frequency chest wall oscillation in patients wih chronic air-flow obstruction. Am Rev Respir Dis 1987;136 (6): 1355-1359.

14. Braverman J, Nozzarella MJ. High-frequency chest compression: advanced therapy for obstructive lung disease. Respir Ther 2007;2:48-51

15. Plioplys AV, Lewis S, Kasnicka I. Pulmonary vest therapy in pediatric long-term care. J Am Med Dir Assoc 2002;3(5):318-321.

16. Lechtzin N, Wolfe LF, Frick KD. The impact of high-frequency chest wall oscillation on healthcare use in patients with neuromuscular diseases. Ann Am Thorac Soc 2016;13(6):904-909.

17. Castagnino M, Vojtova J, Kaminski S, Fink R. Safety of high frequency chest wall oscillation in patient with respiratory muscle weakness. Chest 1996;110:S65.

18. Mahajan AK, Diette GB, Hatipoğlu U, Bilderback A, Ridge A, Harris $\mathrm{VW}$, et al. High frequency chest wall oscillation for asthma and chronic obstructive pulmonary disease exacerbations: a randomized sham-controlled clinical trial. Respir Res 2011;12(1):120.

19. Nicolini A, Grecchi B, Ferrari-Bravo M, Barlascini C. Safety and effectiveness of the high-frequency chest wall oscillation vs intrapulmonary percussive ventilation in patients with severe COPD. Int $\mathrm{J}$ Chron Obstruct Pulmon Dis 2018;13:617-625.

20. Chakravorty I, Chahal A. A pilot study of the impact of high-frequency chest wall oscillation in chronic obstructive pulmonary disease patients with mucus hypersecretion. Int J Chron Obstruct Pulmon Dis 2011;693

21. Keating JM, Collins N, Bush A, Chatwin M. High-frequency chestwall oscillation in a noninvasive-ventilation-dependent patient with type 1 spinal muscular atrophy. Respir Care 2011;56 (11): 1840-1843.

22. Scherer TA, Barandun J, Martinez E, Wanner A, Rubin EM. Effect of high-frequency oral airway and chest wall oscillation and conventional chest physical therapy on expectoration in patients with stable cystic fibrosis. Chest 1998;113(4):1019-1027.

23. Warwick WJ, Hansen LG. The long-term effect of high-frequency chest compression therapy on pulmonary complications of cystic fibrosis. Pediatr Pulmonol 1991;11(3):265-271.

24. Hansen LG, Warwick WJ, Hansen KL. Mucus transport mechanisms in relation to the effect of high frequency chest compression (HFCC) on mucus clearance. Pediatr Pulmonol 1994;17(2):113-118.

25. Varekojis SM, Douce FH, Flucke RL, Filbrun DA, Tice JS, McCoy $\mathrm{KS}$, et al. A comparison of the therapeutic effectiveness of and preference for postural drainage and percussion, intrapulmonary percussive ventilation, and high-frequency chest wall compression in hospitalized cystic fibrosis patients. Respir Care 2003;48(1):24-28.

26. Tomkiewicz RP, Biviji A, King M. Effects of oscillating air flow on the rheological properties and clearability of mucous gel simulants. Biorheology 1994;31(5):511-520.

27. Cobos-Carbó A, Augustovski F. Declaración CONSORT 2010: actualización de la lista de comprobación para informar ensayos clínicos aleatorizados de grupos paralelos. Med Clínica 2011;137(5):213215.

28. Postiaux G, Maffei P, Villiot-Danger J-C, Dubus J-C. La kinésithérapie respiratoire dans la bronchiolite virale aiguë du nourrisson. Arguments pour/contre. Rev Mal Respir 2018;35(4):403415.

29. Wang EEL, Milner RA, Navas L, Maj H. Observer agreement for respiratory signs and oximetry in infants hospitalized with lower respiratory infections. Am Rev Respir Dis 1992;145(1):106-109.

30. Gajdos V, Beydon N, Bommenel L, Pellegrino B, de Pontual L, Bailleux $\mathrm{S}$, et al. Inter-observer agreement between physicians, nurses, and respiratory therapists for respiratory clinical evaluation in bronchiolitis. Pediatr Pulmonol 2009;44(8):754-762.

31. Luarte-Martínez S, Rodríguez-Núñez I, Astudillo P, Manterolab C. Propiedades psicométricas de las escalas de gravedad de obstrucción bronquial en pediatría. Revisión sistemática y metaanálisis. Arch Argent Pediatr 2017;115(3):241-248

32. Piedimonte G, Perez MK. Respiratory syncytial virus infection and bronchiolitis. Pediatr Rev 2014;35(12):519-530.

33. Bush A, Thomson AH. Acute bronchiolitis. BMJ 2007;335 (7628): 1037-1041.

34. Gajdos V, Katsahian S, Beydon N, Abadie V, de Pontual L, Larrar S, et al. Effectiveness of chest physiotherapy in infants hospitalized with acute bronchiolitis: a multicenter, randomized, controlled trial. PLoS Med 2010;7(9):e1000345.

35. Cecins NM, Jenkins SC, Pengelley J, Ryan G. The active cycle of breathing techniques - to tip or not to tip? Respir Med 1999;93 (9):660-665

36. Patterson JE, Bradley JM, Hewitt O, Bradbury I, Elborn JS. Airway clearance in bronchiectasis: a randomized crossover trial of active cycle of breathing techniques versus Acapella. Respiration 2005;72 (3):239-242.

37. West K, Wallen M, Follett J. Acapella vs. PEP mask therapy: a randomised trial in children with cystic fibrosis during respiratory exacerbation. Physiother Theory Pract 2010;26(3):143-149.

38. Sutton PP, Parker RA, Webber BA, Newman SP, Garland N, LopezVidriero MT, et al. Assessment of the forced expiration technique, 


\section{High-Frequency Chest Wall Compression in Bronchiolitis}

postural drainage and directed coughing in chest physiotherapy. Eur J Respir Dis 1983;64(1):62-68.

39. Osman LP, Roughton M, Hodson ME, Pryor JA. Short-term comparative study of high frequency chest wall oscillation and European airway clearance techniques in patients with cystic fibrosis. Thorax 2010;65(3):196-200.

40. Van Ginderdeuren F, Vandenplas Y, Deneyer M, Vanlaethem S, Buyl R, Kerckhofs E. Effectiveness of airway clearance techniques in children hospitalized with acute bronchiolitis: airway Clearance Techniques in Bronchiolitis. Pediatr Pulmonol 2017;52 (2):225-231.
41. Button BM, Heine RG, Catto-Smith AG, Phelan PD, Olinsky A. Chest physiotherapy, gastro-oesophageal reflux, and arousal in infants with cystic fibrosis. Arch Dis Child 2004;89(5):435-439.

42. Zucker T, Skjodt NM, Jones RL. Effects of high-frequency chest wall oscillation on pleural pressure and oscillated flow. Biomed Instrum Technol 2008;42(6):485-491.

43. Yuan N, Kane P, Shelton K, Matel J, Becker BC, Moss RB. Safety, tolerability, and efficacy of high-frequency chest wall oscillation in pediatric patients with cerebral palsy and neuromuscular diseases: an exploratory randomized controlled trial. J Child Neurol 2010;25 (7):815-821. 